Psicologia Escolar

e Educacional
ARTIGO

DOI: http://dx.doi.org/10.1590/2175-35392020216840

Elocid - e216840

\title{
QUEIXAS ESCOLARES APRESENTADAS POR ESTUDANTES COM ALTAS HABILIDADES / SUPERDOTAÇÃO: RELATO MATERNO
}

\author{
Victor Alexandre Barreto da Cunha ${ }^{1} \mathbb{D}$; Carina Alexandra Rondini ${ }^{2} \mathbb{D}$
}

\begin{abstract}
RESUMO
Estudantes com Altas Habilidades/Superdotação (AH/SD), público-alvo da Educação Especial (PAEE), podem apresentar queixas escolares, quando suas necessidades superiores não são atendidas. $O$ estudo teve como objetivo descrever os tipos de queixas escolares que esses estudantes expressam, por meio do relato materno. Participaram 13 mães, de 29 a 48 anos. As mães foram entrevistadas individualmente, utilizando-se da Entrevista de Anamnese, do Roteiro de Entrevista Semiestruturada para a Família e do Questionário de Capacidades e Dificuldades SDQ-Por. Os resultados demonstraram que as mães recebem queixas escolares de seus filhos na escola, dentre as quais estão os problemas de comportamento, desmotivação em sala de aula, indisciplina e dificuldades na interação social. Todas as mães avaliaram seus filhos dentro do padrão para o comportamento pro-social e não-padrão para os problemas de relacionamento com os colegas. É importante que a escola seja uma rede de apoio para auxiliar no desenvolvimento desses estudantes PAEE.
\end{abstract}

Palavras-chave: Superdotados; queixas escolares; família.

\section{The school complaints presented by students with high ability / giftedness: maternal report}

\begin{abstract}
Students with High Ability / Giftedness, target audience of Special Education can present school complaints when their higher needs are not met. The study aimed to describe the types of school complaints that these students express, through the mother's report. Thirteen mothers, aged 29 to 48 years, participated. The mothers were interviewed individually, using the Anamnesis Interview, the Semi-structured Interview Guide for the Family and the SDQ-Por Abilities and Difficulties Questionnaire. The results showed that mothers receive school complaints from their children at school, which includes behavior problems, demotivation in the classroom, indiscipline and difficulties in social interaction. All mothers rated their children within the standard for pro-social behavior and non-standard for relationship problems with colleagues. It is important that the school is a support network to assist in the development of these students.
\end{abstract}

Keywords: Gifted; school complaints; family.

\section{Quejas escolares presentadas por estudiantes con altas habilidades / superdotación: relato materno}

\section{RESUMEN}

Estudiantes con Altas Habilidades/Superdotación (AH/SD), público-objetivo de la Educación Especial (PAEE), pueden presentar quejas escolares, cuando sus necesidades superiores no son atendidas. El estudio tuvo como objetivo describir los tipos de quejas escolares que esos estudiantes expresan, por intermedio del relato materno. Participaron 13 madres, de 29 a 48 años. Se entrevistaron las madres individualmente, utilizándose de la Entrevista de Anamnese, del programa de Entrevista Semiestructurada para la Familia y del Cuestionario de Capacidades y Dificultades SDQ-Por. Los resultados demostraron que las madres reciben quejas escolares de sus hijos en la escuela, entre las cuales están los problemas de comportamiento, falta de motivación en sala de clase, indisciplina y dificultades en la interacción social. Todas las madres evaluaron sus hijos dentro del patrón para el comportamiento prosocial y no-patrón para los problemas de relacionamiento con los compañeros. Es importante que la escuela sea una red de apoyo para auxiliar en el desarrollo de esos estudiantes PAEE.

Palabras clave: Superdotados; quejas escolares; familia.

${ }^{1}$ Universidade Estadual Paulista - Bauru - SP - Brasil; victorpsico.vc@gmail.com

${ }^{2}$ Universidade Estadual Paulista - São José do Rio Preto - SP - Brasil; carina.rondini@unesp.br 


\section{INTRODUÇÃO}

A Política Nacional de Educação Especial na Perspectiva da Educação Inclusiva enfatiza que a pessoa com Altas Habilidades/Superdotação (AH/SD) demonstra

... potencial elevado em qualquer uma das seguintes áreas, isoladas ou combinadas: intelectual, acadêmica, liderança, psicomotricidade e artes. Também apresentam elevada criatividade, grande envolvimento na aprendizagem e realização de tarefas em áreas de seu interesse. (Brasil, 2008, p. 15).

Assim, os estudantes com AH/SD estão entre aqueles considerados Público-Alvo da Educação Especial (PAEE) e, segundo os dados do Instituto Nacional de Estudos e Pesquisas Educacionais Anísio Teixeira (Inep, 2019), em 2018, foram registrados 22.161 estudantes com AH/SD, em todo o território nacional, no total de 1.014.661 estudantes PAEE. O Atendimento Educacional Especializado (AEE) aos estudantes com AH/SD é garantido por leis, mas a aplicabilidade e a execução dessas leis muitas vezes fica deficitária, em função de fatores como mitos, poucos conhecimentos em relação ao tema, formação acadêmica deficitária, entre outros, os quais culminam na invisibilidade desses estudantes, no ambiente escolar (Pérez \& Freitas, 2011). Nesse sentido, Almeida e Capellini (2005, p. 45) apontam que a “... superdotação ainda se constitui um enigma para a ciência e poucos estudos investigam esse fenômeno no Brasil. Consequentemente, muitos talentos nem mesmo são identificados."

Os estudantes com AH/SD são diferentes, entre seus pares, cada qual com sua singularidade, de modo que é difícil definir um perfil único, para um grupo que é, naturalmente, heterogêneo (Serra, 2008; Cupertino \& Arantes, 2012). Nessa perspectiva, Bergamin (2018, p. 21) destaca que "... um dos desafios atuais é conhecer cada aluno e cada turma, considerar a singularidade de cada um e pluralidade que qualquer sala de aula oferece." A autora também ressalta a importância de o professor mapear os interesses e habilidades do estudante, a fim de que seja possível planejar o que será trabalhado dentro da sala de aula.

Diversos autores, como Winner (1998), Fleith e Alencar (2007), Renzulli (2014), Goulart, Mori, Mesti, Albuquerque e Brandão (2016), mencionam algumas características comuns entre os estudantes com $\mathrm{AH} /$ SD: criatividade, curiosidade, originalidade, diversidade de interesses, facilidade e rapidez em aprender, gosto por desafios, habilidades em áreas específicas, liderança, senso de humor, boa memória, persistência, assincronismo, vocabulário avançado, gosto por pessoas mais velhas e perfeccionismo.

Todavia, a maioria dos estudantes com AH/SD gosta de desafios e, quando as aulas não oferecem desafios, dá-se início ao desinteresse, tédio, dificuldades na interação social, e os professores, em grande parte, não conseguem atendê-los adequadamente. Essas condições contribuem para que essas queixas escolares fiquem mais visíveis, especificamente em sala de aula (Freeman \& Guenther, 2000; Fleith, 2009; Guenther, 2012).

Ao contrário do que se possa imaginar, tais estudantes não estão isentos de apresentar diferentes queixas, no ambiente escolar, tais como perder o interesse das aulas que os não desafiam, ter problemas de comportamento, demonstrar perda de interesse e, por sua vez, não ter suas habilidades superiores atendidas, devido ao mito de que, se têm $A H / S D$, devem se sobressair em todas as áreas do conhecimento, não sendo concebível ter alguma dificuldade de aprendizagem (Pérez, 2002; Rech \& Freitas, 2005).

Algumas das queixas comumente observadas em sala de aula são os problemas de comportamento e desinteresse pelas atividades escolares; muitas vezes, essas queixas escolares estão associadas à falta de estímulos, poucos desafios e aulas extremamente repetitivas (Guenther, 2012; Bergamin, 2018).

Conforme Dazzani, Cunha, Luttigards, Zucoloto e Santos (2014, p. 422), por "queixa escolar entendem-se as demandas formuladas por pais, professores e coordenadores pedagógicos acerca de dificuldades e problemas enfrentados por estudantes no ambiente escolar."

Por esse ângulo, faz-se necessária a compreensão das queixas escolares feitas por esses estudantes, no ambiente escolar, e suas possíveis relações com as $\mathrm{AH} /$ $\mathrm{SD}$, na busca da desmistificação e quebra de paradigmas que comprometem o desenvolvimento desses estudantes PAEE.

Dentre as queixas escolares mais frequentes, estão agitação, indisciplina, brigas e rebeldia (Rodrigues, Campos, \& Fernandes, 2012). Entender quais são os fatores que contribuem para as queixas escolares dos estudantes com AH/SD pode ser muito útil aos professores e à família, com o objetivo de criar, organizar e planejar estratégias de ensino e tornar as aulas estimulantes às potencialidades desses estudantes (Escribano, 2003).

Logo, o professor em sala de aula poderá proporcionar apoio e orientações para os estudantes com AH/SD, no ambiente escolar, de sorte a desenvolver suas habilidades superiores (Freeman \& Guenther, 2000). Desse modo, é importante salientar a importância da formação acadêmica do professor, com o intuito de identificar os estudantes com AH/SD, na escola, oferecendo-Ihes uma educação de qualidade para o desenvolvimento de suas habilidades superiores e também para os demais estudantes em sala de aula (Bergamin, 2018). O professor tem um papel muito relevante na sinalização do estudante com traços de $\mathrm{AH} / \mathrm{SD}$, e, no seu contato diário 
em sala de aula, poderá identificar e reconhecer alguns sinais de habilidades superiores, em algum campo do saber, e fazer uma primeira sinalização desse estudante (Maia-Pinto \& Fleith, 2002; Almeida \& Capellini, 2005; Bergamin, 2018).

Este artigo é parte de uma Dissertação de Mestrado $^{1}$ que teve como objetivo identificar características de estudantes com indicadores de AH/SD, em algum campo do saber, que mães observam em no(a)s filho(a) s e suas relações/associações com queixas escolares e problemas de comportamento.

\section{MÉTODO}

\section{Desenho da pesquisa}

Esta pesquisa tem o caráter qualitativo com delineamento descritivo, com o objetivo de descrever as queixas escolares, recebidas da escola, de estudantes com indicadores de $\mathrm{AH} / \mathrm{SD}$, de acordo com o relato materno.

É importante salientar que a pesquisa está vinculada a um projeto maior, intitulado "Alunos com indicadores de altas habilidades/superdotação: confirmação diagnóstica, formação continuada e implementação do enriquecimento curricular" e está associada ao Projeto Extensionista nomeado "Identificação de estudantes com habilidades superiores e aconselhamento de pais e equipe escolar". A pesquisa está em conformidade com as exigências do Conselho Nacional de Saúde-CNS e teve aprovação do Comitê de Ética em Pesquisa (CEP), da Faculdade de Ciências da Universidade Estadual Paulista - UNESP, campus de Bauru-SP, sob o no 2.225.492, no ano de 2017, obedecendo à Resolução no 466, de 12 de dezembro de 2012 (CONEP, 2012).

\section{Participantes}

Participaram do estudo 13 mães, sendo uma amostra por conveniência, representadas por M1 a M13, cujo(a)s filho(a)s estavam em atendimento para avaliação psicológica e pedagógica, para a confirmação dos indicadores de AH/SD. A idade das mães variou entre 29 e 48 anos, com média de idade ${ }^{2}$ de 36 anos, com desvio-padrão de 5 anos. A faixa etária do(a)s 13 filho(a)s variou de cinco aos 14 anos, com idade ${ }^{3}$ média de nove anos, com desvio-padrão de 2 anos.

O perfil sociodemográfico das mães aponta que doze eram casadas, com ocupações diversas, as quais vão desde diaristas e do lar a neuropsicóloga. Em relação

\footnotetext{
${ }^{1}$ Dissertação de Mestrado - Apoio financeiro: FAPESP/CAPES - Fundação de Amparo à Pesquisa do Estado de São Paulo (FAPESP)/Coordenação de Aperfeiçoamento de Pessoal de Nível Superior (CAPES).

${ }^{2}$ Variável com distribuição normal: $W=0,8866 ; p=0,0948$. Teste de normalidade Shapiro-Wilk.

${ }^{3}$ Variável com distribuição normal: $W=0,9191 ; p=0,3148$. Teste de normalidade Shapiro-Wilk.
}

à escolaridade, $38 \%(n=5)$ possuem o Ensino Médio, apenas três com Mestrado e uma mãe com Doutorado. A maioria das mães $(n=10)$ tem dois filhos e as demais, um ou três filhos.

Verificou-se a prevalência do sexo masculino nos estudantes $(n=7)$, sendo seis caçulas, seis primogênitos e um unigênito. Embora a literatura evidencie que a maior parte das pessoas com AH/SD é constituída de primogênito ou unigênitos, e meninos (Winner, 1998), no presente estudo, a posição entre os irmãos foi igualitária, ou seja, seis caçulas e seis primogênitos.

Os estudantes chegaram ao Centro de Psicologia Aplicada (CPA) de três formas: encaminhamento da escola ( $n=6,46 \%)$, demanda espontânea dos pais ( $n=$ $5,38 \%$ ) ou por indicação de um profissional de saúde ( $n=2,16 \%$ ). Tais estudantes exibiram um desempenho intelectual ${ }^{4}$ de maneira igualitária nas classificações média superior e superior, sendo $31 \%$ em cada.

\section{Local}

O estudo foi desenvolvido no (CPA) de uma Universidade pública do interior paulista, em salas bem iluminadas, climatizadas e em dia e horário agendado com as mães.

\section{Instrumentos}

Foram utilizados os seguintes instrumentos:

Entrevista de anamnese, elaborada pelas docentes Coordenadoras do Projeto Extensionista, composta por 15 itens, os quais objetivam obter informações a respeito do desenvolvimento neuropsicomotor, linguagem, escolarização, comportamento, saúde e história de vida do estudante com traços de AH/SD, coletados por meio dos relatos das mães. $O$ estudo visou os seguintes itens: informações sociodemográficas, idade, estado civil, constelação familiar e escolaridade.

O Roteiro de Entrevista para a família, elaborado por Cunha (2018), é constituído por 16 perguntas abertas, com a finalidade de identificar as características apontadas pelas mães a respeito das AH/SD e queixas escolares advindas da escola. Empregaram-se três perguntas do roteiro, relativas às queixas escolares: $O$ seu filho já enfrentou problemas na escola? Ele teve problemas de queixas escolares? Você considera que seu filho tem problemas de queixas escolares por possuir $A H / S D$ ? Você acha que esses problemas estão relacionados com o fato de ele ser "diferente"?

O Questionário de Capacidades e Dificuldades SDQ-Por, elaborado por Goodman (1997), aplicado às mães, foi usado para identificar comportamentos, emoções, relações interpessoais e problemas de saúde emocional de crianças. Foi traduzido e validado no Brasil por Fleitlich, Cortazar e Goodman (2000) e é

\footnotetext{
${ }^{4}$ Escala Wechsler de Inteligência para Crianças (WISC-IV).
} 
constituído por 25 itens, divididos em cinco subescalas: a) sintomas emocionais; b) problemas de conduta; c) hiperatividade; d) problemas de relacionamento com os colegas, e) comportamento pró-social, todas contendo cinco itens cada.

\section{Procedimentos de coleta de dados}

Foram respeitados todos os cuidados éticos, obedecendo à Resolução no 466, de 12 de dezembro de 2012 (CONEP, 2012). Depois da aprovação do projeto maior pelo Comitê de Ética em Pesquisa (CEP), as mães foram convocadas para uma reunião, na qual foi explicada a importância da pesquisa e esclarecido que as mesmas poderiam desistir a qualquer momento. Em concordância, leu-se o Termo de Consentimento Livre e Esclarecido (TCLE), do qual, após assinado, as mães receberam uma cópia (CONEP, 2012). A coleta dos dados ocorreu de maneira individual, no ano de 2017, enquanto os encontros foram realizados semanalmente, de acordo com a disponibilidade de cada mãe, podendo ser nos períodos da manhã, tarde ou noite. As sessões tiveram duração aproximadamente de 50 minutos cada, tendo sido feitos cinco encontros para cada participante.

\section{Procedimentos de análise dos dados}

A análise dos dados advindos do Roteiro de Entrevista de Anamnese (perfil sociodemográfico) e SDQ-Por constituiu-se por meio de estatística descritiva (frequências absolutas, frequências relativas, média, desvio-padrão e/ou porcentagens). Adotou-se o Teste de Normalidade Shapiro Wilk, para verificar a normalidade dos dados quantitativos.

Em relação às entrevistas semiestruturadas para a família, essas foram analisadas pelo software IRAMUTEQ (Interface de R pour les Analyses. Multidimensionnelles de Textes et de Questionnaires), para análise de dados textuais (Ratinaud, 2009). É possível fazer análises textuais através do software, com "análise de similitude" (Camargo \& Justo, 2013). Esses autores frisam que “... é uma análise lexical mais simples, porém graficamente bastante interessante, na medida em que possibilita rápida identificação das palavras chave de um corpus." (p. 516). A análise mostra um grafo que representa a ligação entre as palavras do corpus textual da árvore de palavras.

Os textos das entrevistas foram construídos por meio de cada pergunta feita. Os dados textuais originados da entrevista foram transcritos para o LibreOffice e salvos em arquivos com extensão codificada para UTF-8, seguindo-se a recomendação do software IRAMUTEQ.

Diante dos gráficos criados que compõem a árvore de palavras, foi possível visualizar as ocorrências entre as palavras e a conexidade entre elas; desse modo, as palavras em tamanhos maiores, na árvore de palavras, indicam aquelas que tiveram maiores ocorrências, nos discursos dos participantes, enquanto as ramificações/ espessura das linhas, mais grossas ou mais finas, evidenciam as ligações mais fortes ou mais fracas entre as palavras. Nesse sentido, quanto mais grossa for a linha na árvore de palavras, maior será a conectividade entre as palavras, ao passo que o tamanho da letra aponta que a palavra teve maior frequência pelas participantes.

As entrevistas foram gravadas e transcritas na íntegra, visando garantir a fidedignidade das falas das participantes.

\section{RESULTADOS E DISCUSSÃO}

De acordo com os resultados obtidos por meio do roteiro de entrevistas semiestruturadas para a família, o uso do software IRAMUTEQ possibilitou visualizar as palavras mais frequentes e a sua conexidade, nas falas das participantes. Destarte, os resultados serão apresentados em forma de figuras que compõem a árvore de palavras. A primeira pergunta questionou as mães (alguns relatos das mães podem ser visualizados a seguir), se o(a)s filho(a)s já enfrentaram problemas na escola e suas conexões com as queixas escolares.

Comportamento inadequado, por ser muito questionador na sala de aula. Por isso que isso passa ser um problema. Ele desafia muito a professora; ele pensa muito mais rápido do que ele escreve e o desinteresse dele e, às vezes, a escola fica muito chata para ele. Ele sempre quer mais atividades na sala de aula. (M. 6)

Problemas de comportamento, na escola, há alguns meses atrás. Fazia birra e queria sair da sala e de conteúdo não era o suficiente, pois ele já dominava o conteúdo. Ele dizia que não queria ir para a escola, pois já sabia os conteúdos da sala. Ele ficava desmotivado para ir para a escola. A professora de sala sabia das $A H / S D$, porém, tinha medo, pois não tinha nenhuma experiência, seria um caso novo para a professora. (M. 7)

Ela conversa bastante na sala de aula. Ela sempre foi muito falante e, às vezes, atrapalha a classe, em virtude de terminar as atividades rápido demais. Daí a professora não proporciona mais tarefas para desenvolver. (M. 9)

É possível observar, na Figura 1, os problemas verificados no ambiente escolar e queixas escolares desses estudantes PAEE.

Percebe-se, na Figura 1, que as palavras mais frequentes foram: "comportamento", "indisciplina" e "dificuldades". Podem ser visualizadas também as palavras "notas", "escola" e "conteúdo". Constata-se que os estudantes apresentam muitas queixas escolares, no ambiente escolar, segundo os relatos das mães: comportamento inadequado, problemas com a interação social com os colegas de sala, conversa e baixo rendimento acadêmico. Uma das mães afirma que seu(sua) filho(a) 


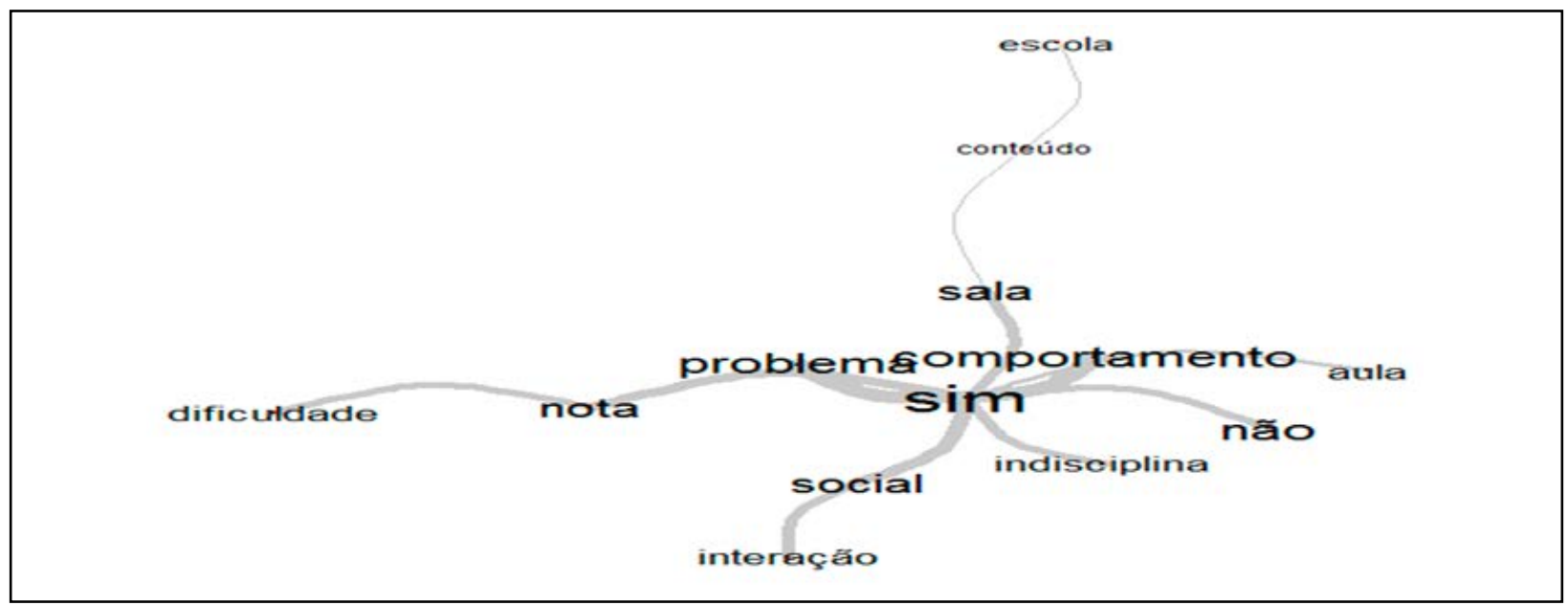

Figura 1. Problemas apresentados pelo(a)s filho(a)s no ambiente escolar e queixas escolares. Fonte: Elaborada pelo IRAMUTEQ.

revela desinteresse pelas aulas, monotonia etc.: "Ele desafia muito a professora, pensa muito mais rápido do que ele escreve e o desinteresse dele é muitas vezes relacionado pelas aulas monótonas" (M. 6).

Nessa linha de pensamento, Fleith (2009) corrobora que, diversas vezes, os estudantes com AH/SD demonstram um baixo rendimento escolar, em virtude de as aulas se tornarem monótonas pela repetição excessiva de conteúdos que o estudante domina e por esses considerarem o ritmo lento da sala de aula.

Em seguida, as mães foram questionadas se acham que seus(suas) filho(a)s têm problemas de queixas escolares por possuir $\mathrm{AH} / \mathrm{SD}$, como mostram os diálogos a seguir:

Com certeza. A professora não vê meu filho com olhar diferenciado e sim como um concorrente, pois ele é muito questionador, em sala de aula, inclusive com a professora. A professora passava uma equação de matemática e levava duas aulas para a resolução do problema, para que todos os alunos pudessem acompanhar a resolução do cálculo. E ele, já na primeira aula, já resolvia a equação. Meu filho precisa de um estímulo a mais, em sala de aula. Por isso que ele chorava, que não queria ir para a escola, pois estava muito desmotivado. Pois, se a professora fosse instruída, ela poderia ter acesso a outros materiais e oferecer mais para ele, pois ele fica tempo ocioso em sala de aula. E esse tempo ocioso ele fica criando perguntas mentalmente para a professora. Ele tem o potencial para fazer mais atividades, em sala de aula. Ele não está sendo estimulado adequadamente, em sala de aula. (M. 6)

Porque ele está na idade certa na classe e muito do conteúdo ensinado pela professora ele já domina. (M. 7)

Acredito que sim. Porque deve ter menos tempo para conversar e aproveita que terminou as tarefas em sala de aula e conversa. (M. 9)

Os professores não possuem o conhecimento das Altas Habilidades e são poucos que têm esse olhar diferenciado. Não explora e nem oferece desafios para as crianças, deixando os alunos desmotivados, em sala de aula. (M. 10)

Pode-se constatar na Figura 2, a conexidade presente nas palavras "professor", "sala de aula" e "olhar



Figura 2. Associação das Queixas escolares com as características das AH/SD.

Fonte: Elaborada pelo IRAMUTEQ. 
diferenciado":

Os resultados indicam que as mães associaram as queixas escolares do(a)s filho(a)s com a presença de características associadas às AH/SD. Alguns professores também não possuíam olhar diferenciado para esses estudantes PAEE, nem Ihes ofereciam situações desafiadoras, estímulos e atividades diversificadas no ambiente escolar; com isso, a desmotivação se instalava em sala de aula. Quanto a esses achados, é de suma importância que os professores ofereçam desafios aos estudantes com AH/SD, em sala de aula, para que sua rotina seja mais atrativa, desafiadora, estimulante e dinâmica, haja vista que esses estudantes são mais rápidos em comparação aos seus pares e necessitam de um olhar diferenciado por parte do corpo docente da escola, bem como a prática de um planejamento de atividades específicas, evitando, assim, o tédio, monotonia e tristeza em sala de aula (Freeman \& Guenther, 2000; Fleith, 2009; Carvalho \& Cruz, 2017; Bergamin, 2018).

Alencar (2007) ressalta que a falta de conhecimento do professor acerca da temática das AH/SD pode prejudicar o desempenho do estudante, dificultando o desenvolvimento de suas potencialidades. Há de se destacar que, muitas vezes, a formação inicial do professor não contempla, na sua grade curricular, atenção aos alunos superdotados, de maneira que cabe à escola implementar práticas de formação continuada, para promover a atualização dos professores, os quais, durante sua formação, tiveram essa lacuna (Sabatella, 2012).

A respeito da terceira pergunta, "As mães foram indagadas se acham que esses problemas estão relacionados com o fato de o(a)s filho(a)s serem 'diferentes', e se houve algum preconceito", eis alguns depoimentos:

Com certeza. Não digo preconceito. Na verdade, ele tirou a professora do sério muitas vezes, por ser muito questionador, em sala de aula. Vejo preconceito por parte dos amigos, em sala de aula, por ele ser gordinho, não sabe jogar futebol, não sabe andar de bicicleta muito bem, não sabe andar de skate e usa óculos. E isso não é bem visto pelos alunos. Querem puni-lo por ele saber, de ser chatinho e muito observador... (M. 6)

Pois, quando você não sabe lidar com uma situação, você vai fugindo e a pessoa se esquiva. Todos os professores que ele passou fizeram isso. Ele está melhor um pouco, pois mudou de escola. Pois o nosso objetivo da atual escola é a socialização do meu filho e a parte emocional, e a escola atual oferece isso. Os alunos devem comentar em casa para as mães sobre a precocidade dele. E também há esses comentários entre os professores... A escola e professores buscam apoiar o meu filho e fornecer mais atividades para ele, em sala de aula. Eu gostaria que a escola fizesse um enriquecimento. Eu vejo que a escola não vai sanar isso sozinha. Hoje os professores têm um conhecimento superficial das AH/SD e não têm conhecimento de como trabalhar com essas crianças. (M. 7)

Acredito que sim. Por ele ser muito bonzinho, entendeu? Eles olhavam pra ele, e por ele ter essa superdotação, ele sempre foi muito parado, prestava atenção em tudo, entendeu...? E esse fato trazia um certo desconforto para os amiguinhos, alguma coisa assim, via que ele era um pouco "bobo". As crianças viam ele como diferente. Os amiguinhos excluíam ele nas atividades de educação física. Eu via preconceito por parte dos amigos. Mas isso está melhorando a cada dia. Todos tentam ajudar o máximo e percebe-se que a escola está empenhada em ajudar a gente. (M. 12)

É possível constatar, na Figura 3, a conexidade presente nas palavras "professor", "preconceito" e "amigo".

Nota-se, nesses discursos, que a mãe M. 6 afirma que seu filho é questionador em sala de aula, enquanto a mãe M. 7 destaca que houve esquiva por parte dos professores, por não saberem identificar e lidar com o estudante com $\mathrm{AH} / \mathrm{SD}$, possivelmente pela falta de estratégias de ensino e pelo fato de muitos terminarem suas atividades com rapidez e ficarem ociosos, dando

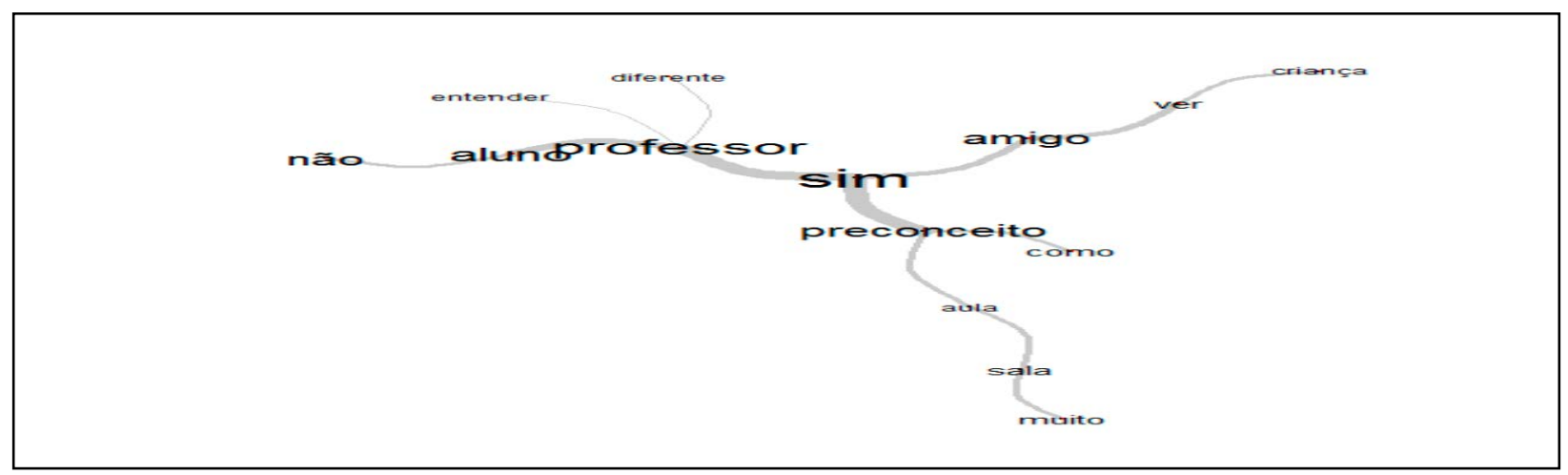

Figura 3. Problemas Relacionados pelo(a) filho(a) ser "diferente". Fonte: Elaborada pelo IRAMUTEQ. 
margem aos questionamentos realizados pelos estudantes, o que pode incomodar o professor. Nessa linha de raciocínio, Guenther (2012, p. 17) salienta que “... crianças intelectualmente dotadas perdem de 50 a $70 \%$ do tempo esperando a professora ensinar o que eles já sabem ou que os colegas completem tarefas que elas já terminaram." Nessa perspectiva, é importante que a equipe escolar entenda as particularidades desses estudantes, evitando mitos e crenças populares que permeiam a sociedade (Sabatella, 2008).

Com relação aos resultados do Questionário de Capacidades e Dificuldades (SDQ-Por), como se pode observar no Gráfico 1, para cada uma das cinco escalas do SDQ-Por, além do total geral, a distribuição para a escala de comportamentos pró-sociais não é gaussiana ${ }^{5}$ ( $p=0.0097$ ).

O Gráfico 1 ilustra que, na escala de sintomas emocionais (SE), 50\% da amostra têm escores entre 0 e 3, o que significa se situarem entre os escores desejados, Goodman (1997).

Em relação à escala de problemas de conduta (PC), verifica-se uma distribuição simétrica, e os escores estão concentrados entre 1 e 3 , que são escores desejados, nos quais se encontram pessoas que estão na mesma categoria não-padrão, com maior pontuação de queixas, equivalente a $50 \%$ da amostra.

Quanto à escala de hiperatividade, $75 \%$ da amostra estão nos escores desejados (0-5). Nos problemas de relacionamento com os pares (PRP), observa-se uma distribuição normal, entretanto, esses resultados mostram que $75 \%$ da amostra exibem escores que estão nos limites estabelecidos como não desejados (2-8) e

${ }_{5}^{5}$ Teste de normalidade de Shapiro-Wilk. apenas $25 \%$ estão nos escores desejados (0-2).

Já no comportamento pró-social (CPS), com distribuição negativamente assimétrica, $100 \%$ da amostra se encontram nos escores desejados (6-10), nesse caso, com menores quantidades de queixas.

No que concerne aos Problemas Totais (PT), percebe-se uma distribuição negativamente assimétrica, indicando que $50 \%$ da amostra em estudo apresentam escores não desejados (17-40) e 50\%, escores desejados, e no limite estabelecido (0-13 e 14-16 respectivamente).

$\mathrm{Na}$ Tabela 1 são apresentados os resultados obtidos por meio do SDQ-Por, as frequências das cinco escalas e o total das dificuldades respondidas pelas mães.

De acordo com os resultados observados na Tabela 1 , verifica-se que, na escala de sintomas emocionais, as mães avaliam que o(a)s filho(a)s estão dentro do esperado. Entretanto, alguns apontamentos são importantes serem tecidos. Apesar de estarem dentro da normalidade, algumas mães disseram que seus filhos, "muitas vezes, queixa-se de dor de cabeça, fica nervoso quando enfrenta situações novas, frequentemente parece triste, deprimido ou choroso".

Para Winner (1998) e Alencar (2007), os estudantes com AH/SD em geral enfrentam algum tipo de sintomas emocionais, em virtude de estarem "fora" de ritmo e velocidade em relação aos seus pares, evidenciando também um perfil de personalidade e qualidade de vida emocional diferenciado de outros estudantes. Assim, Sabatella $(2012$, p. 126) enfatiza que "... a vida intelectual e emocional desses indivíduos é extremamente complexa, construída por uma intrincada e entrelaçada rede de ideias, sentimentos e situações".

No que se refere aos problemas de conduta, as mães descreveram que seus(suas) filho(a)s estão classificados

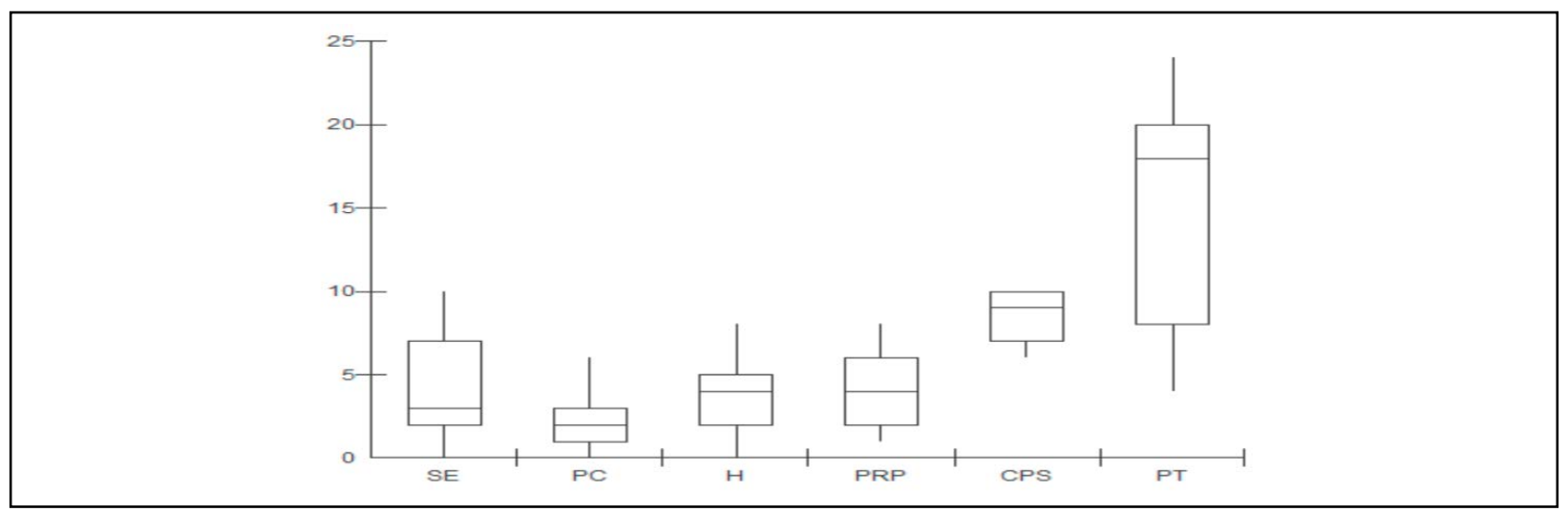

Gráfico 1. Box-Plot dos resultados das escalas do $S D Q^{6}$

Legenda: SE (sintomas emocionais), PC (problemas de conduta), H (hiperatividade), PRP (problemas de relacionamento com pares), CPS (comportamento pró-social) e PT (problemas totais).

${ }^{6}$ SE (Normal 0-3; limítrofe 4; não-padrão 5-10); PC (Normal 0-2; limítrofe 3; não-padrão 4-10); H (Normal 0-5; limítrofe 6; nãopadrão 7-10); PRP (Normal 0-2; limítrofe 3; não-padrão 4-10); CPS (Normal 6-10; limítrofe 5; não-padrão 0-4); PT (Normal 0-13; limítrofe 14-16; não-padrão 17-40) 
Tabela 1. Distribuição de Frequência das escalas no SDQ-Por $(n=13)$.

\begin{tabular}{lcc}
\hline Escala & $\mathbf{n}$ & Categoria \\
\hline \multirow{2}{*}{ Sintomas emocionais } & 7 & Padrão \\
& 1 & Limítrofe \\
\hline \multirow{3}{*}{ Problemas de Conduta } & 5 & Não padrão \\
& 7 & Padrão \\
Hiperatividade & 3 & Limítrofe \\
& 3 & Não padrão \\
\hline \multirow{3}{*}{ Problemas de relacionamento com pares } & 10 & Padrão \\
& 2 & Limítrofe \\
\hline \multirow{2}{*}{ Comportamento pró-social } & 1 & Não padrão \\
& 5 & Padrão \\
& 1 & Limítrofe \\
Total de dificuldades & 7 & Não padrão \\
& 13 & Padrão \\
& 0 & Limítrofe \\
\hline
\end{tabular}

como limítrofes ( $n=3)$ e não-padrão: $(n=3)$ "Frequentemente tem acessos de raiva ou crises de birra."

$\mathrm{Na}$ escala de hiperatividade, as participantes descreveram que seus(suas) filho(a)s estão no "padrão" e, em relação à escala de problemas de relacionamento com os pares, consideraram como na categoria não-padrão ( $n=7)$. Pesquisadoras como Alencar (2001) e Serra e Fernandes (2015) corroboram esses achados, pois, embora os estudantes tivessem relacionamento com seus colegas no âmbito escolar, os pares não demonstravam importância sobre assuntos do seu interesse; em virtude disso, a sua interação social ficava comprometida e, em consequência, o isolamento se tornava presente na vida escolar desses estudantes.

No tocante às pontuações das dificuldades, as mães classificaram seus(suas) filho(a)s como não-padrão. Percebe-se, no estudo, a prevalência de problemas comportamentais/emocionais desses estudantes, conforme é possível conferir no total das dificuldades, de acordo com suas mães.

Já na escala de problemas de relacionamento com os pares, as mães classificaram como não-padrão. Uma hipótese é que os índices elevados de resultados fora do padrão na escala "Problemas de Relacionamento com os colegas" podem estar associados com a dinâmica, no ambiente escolar. Nesse sentido, o professor deverá oferecer desafios a esses estudantes e evitar o ritmo lento de ensino, reduzindo, assim, o sofrimento psicológico ocasionado por repetições excessivas de conteúdos (Winner, 1998; Alencar, 2007; Guenther,
2012; Serra \& Fernandes, 2015).

Todas as mães atribuíram comportamento pró-social aos seus(suas) filho(a)s e responderam que o(a)s filho(a)s têm consideração pelos sentimentos de outras pessoas, boa vontade em compartilhar e se mostram prestativos, se alguém parece magoado, e apontaram como não-padrão para o total das dificuldades.

\section{CONSIDERAÇÕES FINAIS}

O presente estudo teve como objetivo descrever os tipos de queixas escolares, recebidas da escola, de estudantes com indicadores de AH/SD, de acordo com o relato materno.

Com os relatos das mães, foi possível identificar que elas recebem queixas de seus(suas) filho(a)s, provenientes da escola. Dentre essas queixas estão os problemas de comportamento, indisciplina e dificuldades na interação social com estudantes da mesma faixa etária. As mães consideram que as queixas escolares estão intimamente relacionadas ao fato de o(a)s filho(a) $s$ possuírem $A H / S D$. É imperioso que a escola seja uma rede de apoio e parceira da família em mapear os interesses dos estudantes com AH/SD, com vistas ao desenvolvimento de suas habilidades superiores. Cabe destacar a importância da educação continuada aos professores, a fim de que possam trabalhar com esses estudantes de maneira eficaz e inclusiva, para que os mesmos possam desenvolver suas potencialidades.

As mães avaliaram seus filhos dentro da normalidade para as subescalas de sintomas emocionais, pro- 
blemas de conduta, hiperatividade e comportamento pró-social, e abaixo do esperado, para os problemas de relacionamento com os colegas e total das dificuldades.

A literatura confirma que os estudantes com $\mathrm{AH} /$ SD apresentam comportamentos pró-sociais, como, por exemplo, estão prontos para ajudar seus companheiros, compartilhar informações (Guenther, 2012), exibem empatia, espírito de justiça e moral (Winner, 1998), comportamentos os quais estão presentes na vida desses estudantes desde tenra idade.

Os pais devem ser ouvidos no processo de sinalização/identificação e precisam ser parceiros da escola, para o processo de desenvolvimento desses estudantes, pois eles são, mesmo que não tendo conhecimento específico, sem saber nomear, os primeiros a perceber algo "diferente" em seus(suas) filho(a)s. Há que se ter um trabalho colaborativo entre a escola e a família, de sorte que esse processo seja menos problemático e mais eficiente para o desenvolvimento do estudante, sobretudo com AH/SD.

\section{REFERÊNCIAS}

Alencar, E. M. S. (2001). Criatividade e a educação de Superdotados. Petrópolis: Vozes.

Alencar, E. M. S. (2007). Características socioemocionais do superdotado: questões atuais. Psicologia em Estudo, 12 ( 2), 371-378.

Almeida, M. A.; Capellini, V. L. M. F. (2005). Alunos talentosos: possíveis superdotados não notados. Educação, 55 (1), 45-64.

Bergamin, A. C. (2018). Enriquecimento curricular na classe comum a partir das necessidades de alunos com altas habilidades/superdotação (Dissertação de Mestrado em Docência para a Educação Básica). Universidade Estadual Paulista. Faculdade de Ciências, Bauru.

Brasil. (2008). Política Nacional de Educação Especial na Perspectiva da Educação Inclusiva. Brasília. Grupo de Trabalho da Política Nacional de Educação Especial.

Camargo, B. V.; Justo, A. M. (2013). Iramuteq: Um Software Gratuito para Análises de Dados Textuais. Temas em Psicologia, 21 (2), 513-518.

Carvalho, M. L. D.; Cruz, J. Z. (2017). Por que Escola, Por que Estudantes sobredotados com insucesso escolar. Educação \& Realidade, 42 (3),1143-1159.

Conselho Nacional de Saúde [CONEP]. (2012). Resolução no 466, de 12 de dezembro. Brasília: CONEP

Cunha, V. A. B. (2018). Estudantes com indicadores de Altas habilidades/superdotação e queixas escolares: concepção de suas mães. (Dissertação de Mestrado em Psicologia do Desenvolvimento e Aprendizagem). Universidade Estadual Paulista. Faculdade de Ciências, Bauru.

Cupertino, C. M. B.; Arantes, D. R. B. (Eds.). (2012). Um olhar para as altas habilidades: construindo caminhos (2a. ed.). São Paulo: Secretaria da Educação.
Dazzani, M. V. M.; Cunha, E. O.; Luttigards, P. M.; Zucoloto, P. C. S. V.; Santos, G. L. (2014). Queixa escolar: uma revisão crítica da produção científica nacional. Psicologia Escolar e Educacional, 18(3), 421-428.

Escribano, M. C. L. (2003). Análisis de Las Características y Necesidades de Las Famílias com Hijos Superdotados: Propuesta y evaluación de um programa de intervención psicoeducatica em el contexto famíliar (Tese de Doutorado). Universidad Complutense de Madrid.

Fleith, D. S. (2009). Mitos e fatos sobre os superdotados. In Fávero, O. ; Ferreira, W. ; Ireland, T. ; Barreiros, D. (Eds.), Tornar a educação inclusiva (pp. 199-212). Brasília: Unesco.

Fleith, D. S.; Alencar, E. S. (2007). Desenvolvimento de talentos e altas habilidades. São Paulo: Artmed.

Fleitlich, B. W.; Cortazar, P.G.; Goodman, R. (2000). Questionário de Capacidades e Dificuldades (SDQ). Revista Infanto, 8(44), 44-50.

Freeman, J.; Guenther, Z. C. (2000). Educando os mais capazes: ideias e ações comprovadas. São Paulo: EPU.

Goodman, R. (1997). The Strengths and Difficulties Questionnaire: A research note. Journal of Child Psychology and Psychiatry, 38(5), 581-586.

Goulart, A. M. P. L.; Mori, N. N. R.; Mesti, R. L.; Albuquerque, R. A.; Brandão, S. H. A. (2016). Altas Habilidades/ Superdotação: Reflexões e Processo Educacional (2a. ed.) Maringá: Eduem.

Guenther, Z. C. (2012). Crianças dotadas e talentosas... Não as deixem esperar mais! Rio de Janeiro: LTC.

Instituto Nacional de Estudos e Pesquisas Educacionais Anísio Teixeira [INEP]. (2019). Censo da Educação Básica: Sinopse Estatística da Educação Básica - 2018. Brasília: INEP, Ministério da Educação.

Maia-Pinto, R. R.; Fleith, D. S. (2002). Percepção de professores sobre alunos superdotados. Estudos de Psicologia, Campinas, 19(1), 78-90.

Pérez, S. G. P. B. (2002). Da transparência à consciência: uma evolução necessária para a inclusão do aluno com altas habilidades. Trabalho apresentado no 1 o Seminário Estadual de Inclusão de Pessoas com Altas Habilidades/ Superdotados; Seminário de Inclusão da Pessoa com Necessidades Especiais no Mercado de Trabalho, Vitória.

Pérez, S. G. P. B.; Freitas, S. N. (2011). Encaminhamentos pedagógicos com alunos com altas habilidades/ superdotação na educação básica: o cenário brasileiro. Educar em Revista, 41, 109-124.

Ratinaud, P. (2009). IRAMUTEQ: Interface de R pour les Analyses Multidimensionnelles de Textes et de Questionnaires [Computer software].

Rech, A. J. D. O.; Freitas, S. N. (2005). O Papel do Professor junto ao aluno com Altas Habilidades. Revista Educação Especial, 25, 1-7.

Renzulli, J. S. (2014). Modelo de enriquecimento para toda a escola: Um plano abrangente para o desenvolvimento de talentos e superdotação. Revista Educação Especial, 
27(50), 539-562.

Rodrigues, M. C.; Campos, A. P. S.; Fernandes, I. A. (2012). Caracterização da queixa escolar no Centro de Psicologia Aplicada da Universidade Federal de Juiz de Fora. Estudos de Psicologia, 29(2), 241-252.

Sabatella, M. L. P. (2008). Talento e Superdotação: problema ou solução? Curitiba: Ibpex.

Sabatella, M. L. P. (2012). Expandir horizontes para compreender

Apoio Financeiro: FAPESP e CAPES alunos superdotados. In Moreira, L. C.; Stoltz, T. (Ed.), Altas habilidades/Superdotação, talento, dotação e educação. Curitiba: Juruá.

Serra, H. (2008). NEE dos disléxicos e/ou sobredotados. Saber (e) Educar, Porto, 13, 137-147.

Serra, H.; Fernandes, A. S. (2015). Será meu filho sobredotado? Porto: Porto Editora.

Winner, E. (1998). Crianças Superdotadas: Mitos e Realidades. Porto Alegre, Artmed

Recebido: 23 de dezembro de 2018

Aprovado: 14 de novembro de 2019 